\title{
Knowledge, attitude and practice of Iraqi mothers towards Vitamin D supplementation to their infants in Baghdad Al -Rusafa 2016
}

\author{
Tamara Abdul Wahab Rasheed *, Hawraa Khalil Taha**, Bekir Abdul Wahab Rasheed ***
}

\begin{abstract}
Background: Routine supplementation of vitamin $D$ to infants is justifiable since vitamin D deficiency, and its consequences are highly prevalent not only in developing countries but worldwide. Maintaining a normal level of vitamin $D$ is crucial in order to have a normal skeletal, as well as, extra-skeletal health. Knowledge of mothers regarding importance of vitamin $D$ supplementation affect the health of their babies in a positive manner if accompanied by appropriate practice.

Objective: To determine the level of knowledge, attitude and practice of Iraqi mothers of under or equal 12 months old infants in Baghdad, AL-Rusafa, regarding vitamin D supplementation for their infants.

Type of the study: A cross-sectional study.

Methods: A descriptive cross sectional, questionnaire-based study conducted at six primary health care centers in Baghdad AL-Rusafa. 400 mothers of under or equal 12 months old infants attending primary health care centers (PHCC)for routine vaccination and follow up of their infants were included in the study from the $10^{\text {th }}$ of February 2016 till the $10^{\text {th }}$ of June 2016 .
\end{abstract}

Results: A total of 400 mothers enrolled in the study, with a mean age of 27.11 years \pm 6.65572 , Only $(45 \%)(n=180)$ of them had given their infants vitamin $D$ drops, with a mean score of vitamin $D$ supplementation practice of $1.26 \pm 1.51265$ from 4 which was significantly correlated with their knowledge score which was $3.6100 \pm 2.14987$ from 9 and their attitude score which was $3.6275 \pm 1.89644$ from 6 .

Conclusion: The study revealed poor knowledge, fair attitude and poor practice among mothers regarding vitamin D supplement for their infants.

Key words: mother, vit D, Baghdad.

\section{Al-Kindy College Medical Journal 2017: Vol. 13 No.2 Page: 111-116}

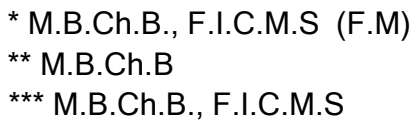

Received 22 $2^{\text {th }}$ May 2017, accepted in final $24^{\text {th }}$ Aug 2017 Corresponding to: Tamara Abdul Wahab Rasheed
$\mathrm{V}$ itamin D is a fat soluble vitamin that has several important functions. (1) It plays an important role in bone metabolism through regulation of calcium and phosphate homeostasis and may also play an important role in modulation of cell growth, neuromuscular, immune function and reduction of inflammation.(2) Vitamin D is produced by the body during exposure to sunlight, but is also found in oily fish, eggs and fortified food products.(1) Neonatal vitamin D levels are dependent on the maternal vitamin $D$ status at delivery.(3) In the first few months of life,. infants are dependent on breast milk, sunlight or supplements as sources of vitamin D..(4) As the breast milk is a poor source of vitamin D, and sun exposure may be restricted for infants living at higher latitudes or for cultural or other reasons, infants are particularly vulnerable to vitamin D deficiency.(4)(5) vitamin D deficiency in infants can lead to bone malformation (rickets), seizures and difficulty breathing.(4) While studies have identified a lack of sun exposure as the main cause of vitamin $D$ deficiency this does not preclude the existence of vitamin $D$ deficiency in hot sunny countries. ${ }^{(6)}$ Indeed, there is evidence that the prevalence of rickets and vitamin $D$ deficiency is greater in the Middle East than in many western countries, with a large meta-analysis concluding that $20-80 \%$ suffer from vitamin $D$ deficiency. (7) American Academy of Pediatrics (AAP) recommends vitamin $D$ supplementation of all breastfed infants in the amount of
400IU/day, started soon after birth and given until the infant is taking more than $1000 \mathrm{~mL} /$ day of vitamin $\mathrm{D}$ fortified whole or formula milk. ${ }^{(8)}$

Aim of the study: To determine the level of knowledge, attitude and practice of mothers regarding Vitamin D supplementation to their infants.

\section{Methods}

1- Study Design: A cross-sectional descriptive study. 2- Setting: The study was conducted in four months duration from the $10^{\text {th }}$ of February 2016 till the $10^{\text {th }}$ of June 2016, in six primary health care centers in Baghdad, AL-Rusafa selected from five different sectors

3- Sample size: A systematic random sample of 422 mothers of under 12 month old healthy infants, attending the selected PHCCs for routine vaccination and follow up of their infants were interviewed. Mothers of unhealthy infants and who refused to participate in the study were excluded (22 mothers).

4- Data Collection: A questionnaire was designed by the researcher adapted from multiple questionnaires of international researches to collect data on mothers knowledge, attitude and practice towards vitamin D. The questionnaire consist of four parts:

Maternal socio-demographic: A list of (4) items covered maternal socio-demographic variables that included age, parity, occupation and education. 
1. Knowledge test part: $A$ list of (9) items testing mothers knowledge regarding vitamin $D$ knowledgement, sources of information, sources of vitamin $D$, role of vitamin $D$, vitamin $\mathrm{D}$ deficiency complications and at which age to start supplementation.

2. Attitude test part: A list of (6) close end questions that evaluated mother's attitude toward vitamin D supplementation to their infant.

3. practice test part : A list of (4) questions that evaluate mothers practice toward giving, or not giving vitamin $D$ to their infants at the time of interview, the age at which vitamin $D$ was started, for how long to be given to their infants, and who prescribe it.

Questionaire scoring: Knowledge responses were divided into three categories according to the attained score. A score of 0-3 (poor), 4-6 (fair), and 7-9 (good) knowledge. Attitude responses were divided into three categories A score of 0-2 (poor), 3-4 (fair), and 5-6 (good) attitude. The supplementation practice responses were divided into two categories according to the attained score. A score of 0-2 (poor), while 3-4 reflected (good) practice.

Statistical analysis: Data were analyzed using SPSS (statistical package for social sciences) version 20/IBM. Descriptive statistics were expressed as: Frequency, Percent and mean $\pm S D$ (standard deviation).

Using the descriptive statistics and Pearson's correlations, level of significance was set at $p$-value (sig.) $\leq 0.05$ to be considered as significant difference.

\section{Results}

Maternal Socio-Demographic Data: The total study sample included 400 mothers of $0-12$ months old infant. Fifty percent the of the participants aged between 26-35 years with a mean of $27.11 \pm 6.65572$, about two third of them $(64.5 \%)$ were multiparous, the majority of them (79\%) were housewives, regarding educational level its shown that $37 \%$ of them were university graduate and higher education( Master or PhD), (table1) Vitamin D is a fat soluble vitamin that has several important functions. (1) It plays an important role in bone metabolism through regulation of calcium and phosphate homeostasis and may also play an important role in modulation of cell growth, neuromuscular, immune function and reduction of inflammation.(2) Vitamin $D$ is produced by the body during exposure to sunlight, but is also found in oily fish, eggs and fortified food products.(1)Neonatal vitamin D levels are dependent on the maternal vitamin $D$ status at delivery.(3) In the first few months of life,. infants are dependent on breast milk, sunlight or supplements as sources of vitamin D..(4) As the breast milk is a poor source of vitamin $D$, and sun exposure may be restricted for infants living at higher latitudes or for cultural or other reasons, infants are particularly vulnerable to vitamin D deficiency.(4)(5)Vitamin D deficiency in infants can lead to bone malformation (rickets), seizures and difficulty breathing.(4)While studies have identified a lack of sun exposure as the main cause of vitamin $D$ deficiency this does not preclude the existence of vitamin $D$ deficiency in hot sunny countries.(6)Indeed, there is evidence that the prevalence of rickets and vitamin D deficiency is greater in the Middle East than in many western countries, with a large meta-analysis concluding that $20-80 \%$ suffer from vitamin D deficiency. (7) American Academy of Pediatrics (AAP) recommends vitamin $D$ supplementation of all breastfed infants in the amount of $400 \mathrm{IU} /$ day, started soon after birth and given until the infant is taking more than $1000 \mathrm{~mL} /$ day of vitamin Dfortified whole or formula milk. ${ }^{(8)}$

Objective of the study:To determine the level of knowledge, attitude and practice of mothers regarding Vitamin D supplementation to their infants.

\section{Methods}

1- Study Design: A cross-sectional descriptive study. 2- Setting: The study was conducted in four months duration from the $10^{\text {th }}$ of February 2016 till the $10^{\text {th }}$ of June 2016, in six primary health care centers in Baghdad, AL-Rusafa selected from five different sectors

3- Sample size: A systematic random sample of 422 mothers of under 12 month old healthy infants, attending the selected PHCCs for routine vaccination and follow up of their infants were interviewed. Mothers of unhealthy infants and who refused to participate in the study were excluded (22 mothers).

4- Data Collection: A questionnaire was designed by the researcher adapted from multiple questionnaires of international researches to collect data on mothers knowledge, attitude and practice towards vitamin $\mathrm{D}$. The questionnaire consist of four parts:

1. Maternal socio-demographic: A list of (4) items covered maternal socio-demographic variables that included age, parity, occupation and education.

2. Knowledge test part: A list of (9) items testing mothers knowledge regarding vitamin $D$ knowledgement, sources of information, sources of vitamin $D$, role of vitamin $D$, vitamin $\mathrm{D}$ deficiency complications and at which age to start supplementation.

3. Attitude test part: A list of (6) close end questions that evaluated mother's attitude toward vitamin D supplementation to their infant.

4. practice test part : A list of (4) questions that evaluate mothers practice toward giving, or not giving vitamin $D$ to their infants at the time of interview, the age at which vitamin $D$ was started, for how long to be given to their infants, and who prescribe it.

Questionaire scoring: Knowledge responses were divided into three categories according to the attained score. A score of 0-3 (poor), 4-6 (fair), and 7-9 ( good) knowledge. Attitude responses were divided into three categories A score of 0-2 (poor), 3-4 (fair), and 5-6 (good) attitude. The supplementation practice responses were divided into two categories according to the attained score. A score of $0-2$ (poor), while 3-4 reflected (good) practice.

5- Statistical analysis: Data were analyzed using SPSS (statistical package for social sciences) version 20/IBM. Descriptive statistics were expressed as: Frequency, Percent and mean \pm SD (standard deviation).

Using the descriptive statistics and Pearson's correlations, level of significance was set at $p$-value (sig.) $\leq 0.05$ to be considered as significant difference. 
Results

Maternal Socio-Demographic Data: The total study sample included 400 mothers of 0-12 months old infant. Fifty percent the of the participants aged between 26-35 years with a mean of $27.11 \pm 6.65572$, about two third of them $(64.5 \%)$ were multiparous, the majority of them (79\%) were housewives, regarding educational level its shown that $37 \%$ of them were university graduate and higher education( Master or PhD), (table1)

Table 1: Maternal Socio- Demographic Data

\begin{tabular}{|c|c|c|c|}
\hline Variable & & Frequency & Percent \\
\hline \multirow[t]{4}{*}{ Age } & $15-25$ & 150 & 37.5 \\
\hline & $26-35$ & 200 & 50.0 \\
\hline & $36-50$ & 50 & 12.5 \\
\hline & Mean & \multicolumn{2}{|c|}{$27.1100 \pm 6.65572$} \\
\hline \multirow[t]{3}{*}{ Parity } & Primi & 136 & 34.0 \\
\hline & Multi & 258 & 64.5 \\
\hline & Grand-multi & 6 & 1.5 \\
\hline \multirow[t]{3}{*}{ Occupation } & Housewife & 316 & 79.0 \\
\hline & Employed & 76 & 19.0 \\
\hline & Student & 8 & 2.0 \\
\hline \multirow[t]{6}{*}{ Education } & Illitrate & 4 & 1.0 \\
\hline & Read \& Write & 20 & 5.0 \\
\hline & Primary School & 90 & 22.5 \\
\hline & Secondary School & 138 & 34.5 \\
\hline & University & 140 & 35.0 \\
\hline & Master or PhD & 8 & 2.0 \\
\hline
\end{tabular}

\section{Results of knowledge questions}

About $71.5 \%$ (286) of participants heard about vitamin D. While $28.5(n=114)$ of them didn't have information about vitamin D. (table 2)

Table 2: Participant's responses towards knowledge questions $(\mathrm{N}=400)$

\begin{tabular}{|c|c|c|}
\hline Question & $\begin{array}{c}\mathrm{N} \text { of correct } \\
\text { answer }\end{array}$ & $\begin{array}{c}\% \text { of correct } \\
\text { answer }\end{array}$ \\
\hline Have heard about Vitamin D & 286 & $71.5 \%$ \\
\hline Sources of vitamin D (sun exposure, food, supplement...) & 154 & $38.5 \%$ \\
\hline Sufficiency of breast milk with vitamin D & 57 & $14.25 \%$ \\
\hline Sufficiency of fruits and vegetables with vitamin D & 42 & $10.5 \%$ \\
\hline Dietary sources of vitamin D & 243 & $60.75 \%$ \\
\hline Vitamin D supplements are best started during first month & 76 & $19 \%$ \\
\hline Vitamin D is important for bone growth and immunity & 241 & $60.25 \%$ \\
\hline Vitamin D helps the body to absorb calcium & 257 & $64.25 \%$ \\
\hline Vitamin D deficiency cause Rickets, Diabetes, asthma and decrease immunity & 88 & $22 \%$ \\
\hline
\end{tabular}

Remarkably, the mean knowledge score was $3.61 \pm 2.14987$ from 9 indicating poor knowledge about vitamin $D$ among mothers, (table 3)

Table 3: frequency of knowledge score among the group

\begin{tabular}{|c|c|c|}
\hline & $\mathrm{N}$ & Percent \\
\hline Poor & 192 & $48.0 \%$ \\
\hline Fair & 166 & $41.5 \%$ \\
\hline Good & 42 & $10.5 \%$ \\
\hline Mean \pm Standard Deviation & \multicolumn{2}{|c|}{$3.6100 \pm 2.14987$} \\
\hline
\end{tabular}

Maternal Attitude towards vitamin D supplementation

The majority of responding mothers $75.25 \%(n=301)$ agreed that vitamin $D$ supplementation are necessary to their infants, and $86.75 \%(n=347)$ showed willingness to administer vitamin $D$ supplements to their infants if a doctor offered them, (table 4) 
Table 4: Participant's responses in attitude towards Vitamin D supplementations

\begin{tabular}{|c|c|c|c|}
\hline Maternal attitude toward vitamin D supplementation & Agree & Disagree & Don't know \\
\hline $\begin{array}{l}\text { I think that Vitamin D supplement is necessary to } \\
\text { my infant }\end{array}$ & $\begin{array}{c}301 \\
(75.25 \%)\end{array}$ & $\begin{array}{c}12 \\
(3 \%)\end{array}$ & $\begin{array}{c}87 \\
(21.75 \%)\end{array}$ \\
\hline $\begin{array}{c}\text { If I was given Vitamin D supplement by a doctor I } \\
\text { will give it to my infant }\end{array}$ & $\begin{array}{c}347 \\
(86.75 \%)\end{array}$ & $\begin{array}{c}14 \\
(3.5 \%) \\
\end{array}$ & $\begin{array}{c}39 \\
(9.75 \%)\end{array}$ \\
\hline $\begin{array}{l}\text { In my opinion, Since my baby is breast-fed he(she) } \\
\text { does not need vitamin D supplement than if he } \\
\text { (she) was on milk formula }\end{array}$ & $\begin{array}{c}209 \\
(52.25 \%)\end{array}$ & $\begin{array}{c}146 \\
(36.5 \%)\end{array}$ & $\begin{array}{c}45 \\
(11.25 \%)\end{array}$ \\
\hline $\begin{array}{l}\text { In my opinion, since my baby is being exposed to } \\
\text { sunlight he(she ) does not need vitamin D drops }\end{array}$ & $\begin{array}{c}156 \\
(39 \%)\end{array}$ & $\begin{array}{c}150 \\
(37.5 \%)\end{array}$ & $\begin{array}{c}94 \\
(23.5 \%)\end{array}$ \\
\hline $\begin{array}{c}\text { Since I am on vitamin D supplement, my baby does } \\
\text { not need Vitamin D drops. }\end{array}$ & $\begin{array}{c}116 \\
(29 \%)\end{array}$ & $\begin{array}{c}195 \\
(48.75 \%)\end{array}$ & $\begin{array}{c}89 \\
(22.25 \%)\end{array}$ \\
\hline $\begin{array}{l}\text { I will advise my relative or friends to give vitamin D } \\
\text { supplements to their infants }\end{array}$ & $\begin{array}{c}306 \\
(76.5 \%)\end{array}$ & $\begin{array}{c}8 \\
(2 \%) \\
\end{array}$ & $\begin{array}{c}86 \\
(21.5 \%) \\
\end{array}$ \\
\hline
\end{tabular}

The overall mean attitude score of the respondents was 3.6275 \pm 1.89644 which indicate fair (positive) attitude towards vitamin $\mathrm{D}$, (table 5)

Table 5: frequency of attitude score among the group

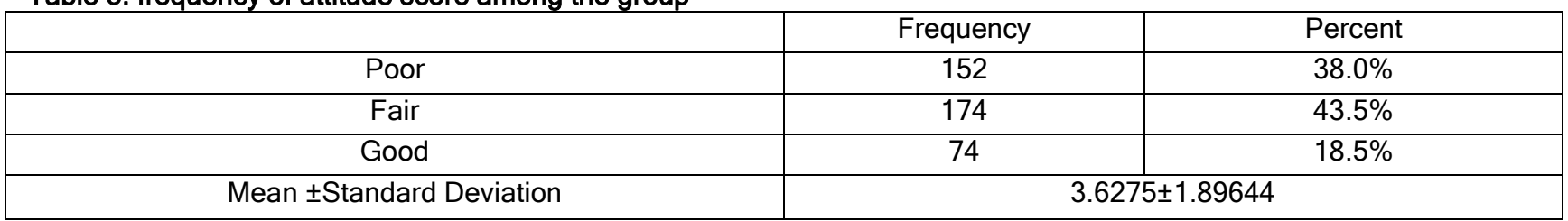

Maternal Practice towards vitamin D: Regarding vitamin D supplementation practice in this study only (45\%) of the total participants were giving their infants vitamin D drops, (table 6) The mean practice score of vitamin D supplementation were 1.26 from 4 with a standard deviation of 1.51265 which indicate poor practice, (table 7)

Table 6: Maternal practice toward vitamin D supplementation

\begin{tabular}{|c|c|c|c|c|}
\hline \multicolumn{2}{|l|}{ Practice } & & & \\
\hline \multirow{2}{*}{\multicolumn{2}{|c|}{ Mother giving Vitamin D Drops }} & \multicolumn{2}{|c|}{$\begin{array}{l}\text { Yes }=180 \\
(45 \%)\end{array}$} & $\begin{array}{c}\text { No }=220 \\
(55 \%)\end{array}$ \\
\hline & & $\mathrm{n}=180$ & $\%$ from 180 & \\
\hline \multirow[t]{3}{*}{ Age supplement Started } & $0-3$ months & 38 & $21.1 \%$ & \\
\hline & $4-6$ months & 80 & $44.45 \%$ & \\
\hline & $>6$ months & 62 & $34.45 \%$ & \\
\hline \multirow{3}{*}{$\begin{array}{c}\text { Frequency of supplementation } \\
\text { Day per week }\end{array}$} & Daily & 114 & $63 \%$ & \\
\hline & 3days/ week & 58 & $32 \%$ & \\
\hline & $<3$ days/ week & 8 & $5 \%$ & \\
\hline \multicolumn{2}{|c|}{ Duration of giving supplementation of vitamin D } & \multicolumn{3}{|c|}{ Mean $=5.2833 \pm 3.54133$ months } \\
\hline
\end{tabular}

Table 7: frequency of practice score among the group

\begin{tabular}{|c|c|c|}
\hline & No. & Percent \\
\hline Poor & 306 & $76.5 .0 \%$ \\
\hline Good & 94 & $23.5 \%$ \\
\hline Mean \pm Standard Deviation & & $1.26 \pm 1.51265$ \\
\hline
\end{tabular}

all practice score and knowledge score, practice score and attitude score and knowledge score with attitude score showed, a positive and significant correlations with $\mathrm{P}<0.0001$ 
Table 8: Correlation between Knowledge, attitude and practice

\begin{tabular}{|c|c|c|c|c|}
\hline 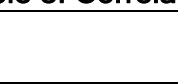 & Mean \pm S.D & $\begin{array}{c}\text { Correlation with } \\
\text { Knowledge }\end{array}$ & $\begin{array}{c}\text { Correlation with } \\
\text { Attitude }\end{array}$ & $\begin{array}{c}\text { Correlation with } \\
\text { Practice }\end{array}$ \\
\hline Knowledge & $3.61 \pm 2.14987$ & $\star * * *$ & $\begin{array}{c}P=<0.0001^{*} \\
\mathrm{R}^{2}=0.423\end{array}$ & $\begin{array}{c}P=0.0001^{*} \\
R^{2}=0.322\end{array}$ \\
\hline Attitude & $3.6275 \pm 1.89644$ & $\begin{array}{c}P=<0.0001 \\
R^{2}=0.424\end{array}$ & $\star * * * *$ & $\begin{array}{l}P=0.0001^{*} \\
R^{2}=0.453\end{array}$ \\
\hline Practice & $1.26 \pm 1.51265$ & $\begin{array}{c}P=<0.0001 \\
R^{2}=0.268\end{array}$ & $\begin{array}{c}P=<0.0001^{*} \\
R^{2}=0.230\end{array}$ & $* * * * *$ \\
\hline
\end{tabular}

Source of information: When questioning about the source of getting advice to give vitamin D supplement, $76 \%$ of them the source was private doctor, while only $13 \%$ was the PHCC doctors

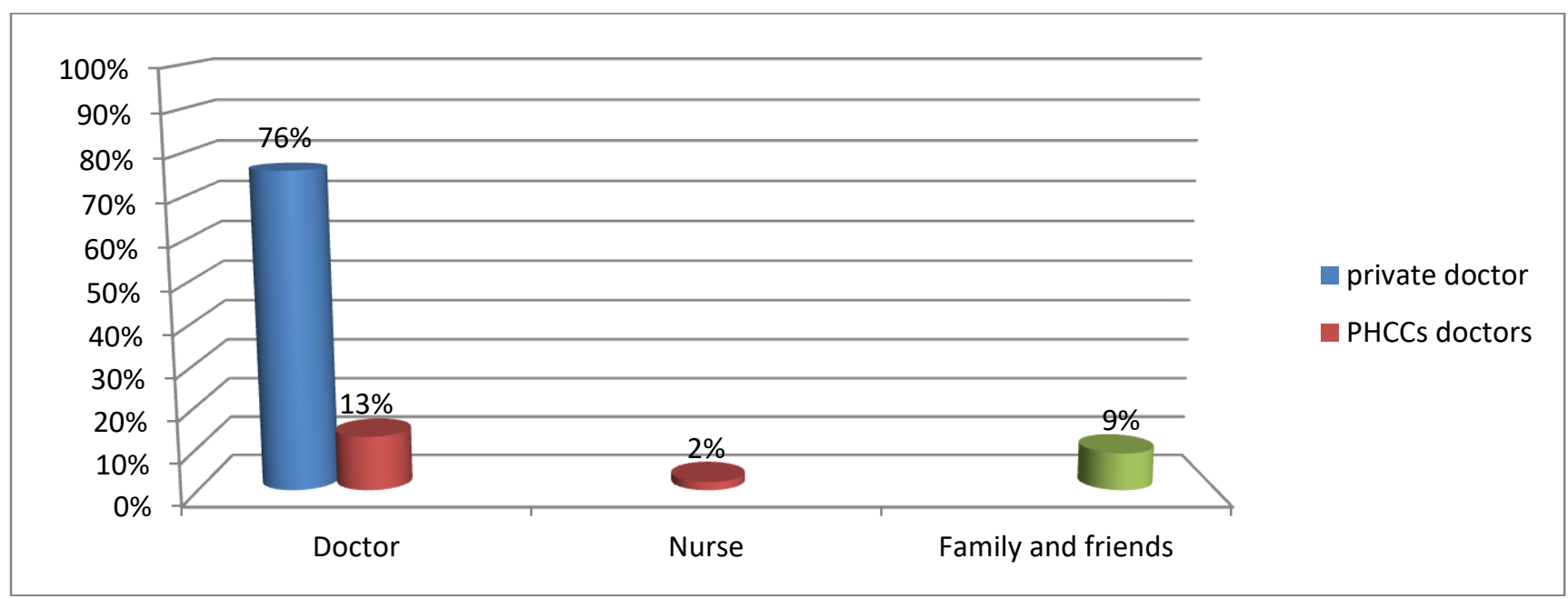

Figure-1-: Source of information

Discussion : The sample maternal Socio- Demographic Data is similar to a study conducted by Alramdhan A, et al. in Al-Absa, Eastern Saudi Arabia at 2012. ${ }^{(9)}$ And also similar to a recent study published by Al Marzooqi D, et al. in 2014 in UAE, except in employment status and educational level, in which $(59.4 \%)$ of emirates mothers were housewife, and (68.3\%) of them were university graduates. (10) The poor knowledge about vitamin D among Iraqi mothers in our study, goes with $\mathrm{Al}$ Marzooqi D,et al. in UAE at 2014 who found that the mean knowledge score was 1.88 out of 6 indicating also poor knowledge about vitamin $\mathrm{D}$ among Emirates mothers. ${ }^{(10)}$ In this study, only $19 \%$ of mothers were aware that vitamin D supplementation should be started within one week of birth. This rate was considerably low which goes with Cicek Z,et al. in Konya, Turkey at 2015 study, where $32 \%$ of Turkish mothers were aware that the supplementation should be started within one week of birth. ${ }^{(11)}$ On the other hand, more than $60 \%$ are not aware of the nutritional sources of vitamin $D$, and only $14.25 \%$ were aware about the insufficiency of breast milk in vitamin $D$, which is considered low percent and also goes with Cicek Z,et al. study, where more than $40 \%$ of Turkish mothers were not aware of the nutritional sources of vitamin D and $40 \%$ considered milk to be a sufficient source of vitamin $D .{ }^{(11)}$ The overall fair attitudes scale towards vitamin $D$ in our study, may be due to their poor knowledge about the insufficiency of the natural sources of vitamin $D$, this result goes with
Al Marzooqi D,et al. in UAE at 2014 result in the same concern. ${ }^{(10)}$ Regarding vitamin D supplementation practice in this study only (45\%) of the total participants were giving their infants vitamin $D$ drops. Of those who gave vitamin D $44.4 \%$ started between 4 to 6 months while only $21.1 \%$ of them started before 4 months of life. This is a relatively a low percent, in comparison to $\mathrm{Al}$ Marzooqi D, et al. in which ( $73.9 \%$ ) of mothers had given their infants vitamin D drops and $(64.1 \%)$ started correctly during the first month of life ${ }^{(10)}$ indicating that this issue, needs to be addressed.

Similar poor vitamin D supplementation practices were reported by Khadrawi, et al. among Muslim mothers and infants both in Ireland and Saudi Arabia, at 2015, where only $(49.4 \%)$ of Ireland Muslim mothers and (13.2\%) of Saudi Muslim mothers were giving their infants vitamin D drops. ${ }^{(12)}$ Good knowledge raises concern among mothers regarding their infant's need for vitamin D supplementations and improves their practice which was proved by our study by positive correlations and significant difference between them, in contrast to $\mathrm{Al}$ Marzooqi D,et al. who showed no significant association between practice and knowledge nor practice and attitude. ${ }^{(10)}$ When questioning about the source of information regarding vitamin $D$ it was found that the majority of participants in our study heard about it commonly from their doctors, in similar to Emirates and Irish mothers in whom the main source of their information were their doctors. ${ }^{(10)(12)}$ The majority of 
mothers who gave vitamin $D$ to their infant, got the advice from private doctors, indicating that appropriate communication about Vitamin D supplementation should be encouraged from health care providers.

Conclusion: From this study we concluded that

- The majority of mothers have poor knowledge about vitamin $\mathrm{D}$, fair attitude and poor practice

- The majority of the mothers who give vitamin $D$ to their infant get advice from their private doctors, while minority of them were advised by the PHCCs doctors.

\section{References}

1. World Health Organization. Vitamin D supplementation in infant. e-Library of Evidence for Nutrition Actions, 22 July 2015.

2. Gupte S. Pedaitric nutrition and nutritional disorders. In : Gupte S (ed) The Short text Book of Pediatrics .11th edition. Jaypee Brothers. New Delhi; 2010:155160.

3. Hollis BW, Wagner CL. Assessment of dietary vitamin $D$ requirements during pregnancy and lactation. Am J Clin Nutr, 2004; 79: 717-26.

4. Gartner LM, Greer FR: American Academy of Pediatrics, Section on Breastfeeding and Committee on Nutrition. Prevention of rickets and vitamin D deficiency: new guidelines for vitamin $D$ intake. Pediatrics 2003; 111(4): 908-910.

5. Robert M. Kliegman, Bonita F. Stanton., Joseph W. St Geme III., Nina F. Schor. Nelson TEXTBOOK of PEDIATRICS. $20^{\text {th }}$ edition. Elsevier publications Philadelphia; 2016: 281.
6. Holick, M.F. Vitamin D deficiency. English Journal of Medicine, 2007; 266-281.

7. El-Hajj Fuleihan G."Vitamin D deficiency in the Middle East and its health consequences for children and adults," Clinical Review Bone Miner Metabolism 2009; (vol. 7): 77-93.

8. American Academy of Family Physician. AAP Doubles Recommended Vitamin D Intake in Children. 2009; 80 (2): 196-198.

13. Hatun S, Bereket A, Ozkan B, Coşkun T, Kose R, Calykoğlu AS. Free vitamin D supplementation for every infant in Turkey. Arch Dis Child, 2007; 92: 373374.

9. Alramdhan AM, \& El-Zubair AG. Poor vitamin D supplementation in infants. Cross-sectional study of maternal practices and awareness of vitamin D supplementation in infants in Al-Ahsa, Eastern Saudi Arabia. Saudi Med J. 2014; 35(1): 67-71.

10. Al-Marzook D, Al-Ameri D, Al-Hayayi $\mathrm{E}$, et al Knowledge, attitude and practice of vitamin $D$ supplementation status among 6 month old infants in Abu Dhabi. International Journal of medical and pharmacological sciences 2016; 7: 232

11. Çiçek Z, Kalkan i\& Sivri B. Determination of the level of knowledge and attitudes of mothers regarding vitamin d use in Konya, Global Journal on Advances in Pure \& Applied Sciences. 2015; 07: 197-203.

12. Khadrawi I, Kearney MJ, Harastani R. Vitamin D Supplementation Practices during Pregnancy and Infancy among a Sample of Muslim Women in Ireland and Saudi Arabia. Journal of Nutrients. 2015; 2(1): 11-26. 